\title{
Penerapan Model Role Playing untuk Meningkatkan Hasil Belajar Front Office Materi Penanganan Check In Tamu Individu
}

\author{
Lila Suryani* \\ Sekolah Menengah Kejuruan Negeri I Dlanggu
}

\section{A R T I C L E I N F O}

Article history:

Received 12 December 2019

Received in revised form

01 January 2020

Accepted 30 January 2020

Available online 27

February 2020

\section{Kata Kunci:}

Hasil belajar, aktivitas, model role playing.

Keywords:

Learning outcomes, activities, role playing models

\begin{abstract}
A B S T R A K
Tujuan penelitian ini adalah untuk mengetahui penerapan Role playing terhadap peningkatan hasil belajar front office materi penanganan check in tamu individu di kelas XI APH2 SMKN 1 Dlanggu. Oleh karena itu penting dilakukan perbaikan melalui penelitian tindakan kelas (PTK) dengan menerapkan pembelajaran model role playing dengan tujuan untuk meningkatkan aktivitas dan hasil belajar siswa yang dilaksanakan dalam dua siklus dimana tiap-tiap siklus terdiri dari dua kali pertemuan. Subjek penelitian adalah siswa kelas XI APH2 SMKN I Dlanggu yang berjumlah 34 orang, yang terdiri dari 9 orang laki-laki dan 25 orang perempuan. Sumber data diperoleh dari guru dan siswa yang berupa data kuantitatif dan kualitatif. Data aktivitas guru dan data aktivitas siswa diperoleh melalui obsevasi yang direkamkan pada lembar observasi serta data hasil belajar siswa diperoleh melalui tes tertulis berupa evaluasi hasil kerja siswa dan evaluasi akhir dan formatif. Hasil penelitian menunjukkan bahwa aktivitas guru, aktivitas siswa, serta hasil belajar siswa meningkat melalui penerapan model role playing. Oleh karena itu disarankan kepada guru, agar secara bertahap dan berkesinambungan mengkaji pola dan strategi pembelajaran yang tepat dalam upaya perbaikan proses dan hasil pembelajaran dimana salah
\end{abstract} satunya adalah model role playing yang telah terbukti dapat meningkatkan aktivitas dan hasil belajar siswa. Dalam proses pembelajaran dengan menggunakan strategi kooperatif, sesuai dengan teori belajar konstruktivisme. Penerapan konstruktivisme dalam proses belajar-mengajar menghasilkan metode pengajaran yang menekankan aktivitas utama pada siswa.

\section{A B S T R A C T}

The purpose of this study was to determine the application of role playing towards improving front office learning outcomes in handling individual guest check-ins in class XI APH2 SMK 1 Dlanggu Therefore, it is important to make improvements through classroom action research (CAR) by implementing role playing model with the aimed to increasing student activity and learning outcomes carried out in two cycles where each cycle consists of two meetings. The subjects of the study were 34 students at XI grade students of APH2 Dlanggu I Dlanggu, consist of 9 men and 25 women. Sources of data obtained from teachers and students in the form of quantitative and qualitative data. Teacher activity data and student activity data obtained through observation recorded on the observation sheet and student learning outcomes data obtained through written tests in the form of evaluating student work and final and formative evaluation. The results showed that teacher activity, student activity, and student learning outcomes improved through the application of role playing models. It recommended to teachers, so that gradually and continuously study the appropriate learning patterns and strategies in an effort to improve the process and learning outcomes where one of them is a role playing model that has been proven to be able to improve student learning activities and outcomes. In the learning process using cooperative strategies, according to constructivism learning theory. The application of constructivism in the teaching-learning process produces teaching methods that emphasize the main activities of students. 


\section{Pendahuluan}

Undang-undang Sistem Pendidikan Nasional Nomor 20 tahun 2003 menyatakan bahwa pembelajaran adalah proses interaksi peserta didik dengan pendidik dan sumber belajar pada suatu lingkungan belajar. Dalam pembelajaran, guru harus memahami hakikat materi pelajaran yang diajarkannya dan memahami berbagai model pembelajaran yang dapat merangsang keemampuan siswa untuk belajar dengan perencanaan pengajaran yang matang oleh guru (Amri dan Ahmadi, 2010) (Basri, 2017).

Front office Department merupakan departmen yang bertanggung jawab atas penjualan kamar.hotel berdasarkan cara yang sistematik melalui reservasi hingga penyerahan kamar kepada tamu hotel dan memberikan pelayanan informasi kepada para tamu hotel selama mereka berada dan menginap dihotel. Dapat dilihat dari definisi diatas bahwa kantor depan merupakan departmen yang memiliki peran an sebagai penjual kamar dan secar langsung merupakan sumber pendapatan utama setiap hotel. Departmen front office memberikan layanan yang penuh kepada tamu dari sebelum tamu menginap,saat kedatangan tamu,selama tinggal dihotel dan saat hendak meninggalkan hotel. Peranan penting front office adalah pemberian informasi ini berarti petugas kantor depan diharapkan mampu memberikan informasi yang jelas,benar dan cepat tentang produk,fasilitas,activitas pelayanan yang ada dihotel maupun di luar hotel, informasi yang diberikan tidak hanya terbatas untuk tamu tetapi informasi yang dibutuhkan oleh kolega atau teman sejawat lainnya.Petugas kantor depan berperan baik aktif dalam hubungan dengan tamu dan masyarakat sekitar agar terjadi hubungan yang harmonis dan berdampak pada pembentukan citra hotel yang baik,.

Kantor depan adalah cerminan dari kualitas hotel untuk pertama kali bagi tamu saat memasuki suatu hotel, untuk itu kesiapan,kesigapan,ketepatan serta kemampuan semua karyawan dibagian kantor depan dalam menjalankan fungsi tugas dan tanggungjawab sangatlah menentukan dalam memberikan impresi baik maupun kurang baik atau buruk pada para tamu hotel sebelum para tamu tersebut mendapatkan pelayanan dan pengalaman yang lainnya saat mereka dating untuk menginap maupn tidak di suatu hotel. Ingat ada dorongan motivasi berupa slogan bagi karyawan kantor depan sebagai berikut" We Do Not Have A Second Chance To Give Good Impressed To Our Quest

Kantor depan hotel (front office) secara operasional berhubungan dengan tamu dan area kerjanya tidak jauh dari lobi, daerah yang paling ramai hilir mudik tamunya. Oleh karena itu bagian ini disebut dengan bagian front office. Kantor depan hotel merupakan salah satu bagian dari hotel yang paling penting dalam hal mewujudkan tujuan yang akan dicapai oleh hotel. Tujuan dari kantor depan hotel adalah sebagai berikut :

1. Meningkatkan tingkat hunian kamar serta pendapatan hotel.

2. Meningkatkan jumlah tamu langganan.

3. Memenuhi kebutuhan dan kepuasan tamu secara baik, tepat dan cepat kepada tamu.

4. Membentuk citra hotel yang positif.

Kantor depan hotel memiliki fungsi dalam mewujudkan tujuan dari hotel. Fungsi tersebut dilakukan oleh petugas kantor depan sehari-hari, adapun fungsi-fungsi tersebut adalah sebagai berikut.

1. Menjual kamar, kegiatan yang dilakukan antara lain: menerima pemesanan kamar, melakukan pendaftaran tamu, dan memblok kamar

2. Memberikan informasi mengenai seluruh produk, fasilitas, pelayanan dan aktivitas baik yang ada di hotel maupun diluar hotel.

3. Mengkoordinasikan kepada bagian lain yang terkait dalam rangka memenuhi keinginan tamu serta memberikan pelayanan yang maksimal.

4. Melaporkan status kamar yang terkini.

5. Mencatat, memeriksa pembayaran tamu serta menangani rekening tamu.

6. Membuat laporan yang dibutuhkan oleh hotel.

7. Memberikan pelayanan telekomunikasi untuk tamu.

8. Memberikan pelayanan barang bawaan tamu.

9. Menyelesaikan keluhan tamu.

Banyak faktor yang menyebabkan hasil belajar dan prestasi belajar Front office Materi Penanganan Check In Tamu Individusiswa di SMKN I Dlanggu tidak sesuai dengan tujuan yang diharapkan di antaranya peserta didik tidak memiliki kemampuan menggunakan penalaran pada pola dan sifat serta kemampuan dalam membuat generalisasi materi dalam menyimpulkan pembelajaran. Selain itu faktor yang sangat mempengaruhi kesulitan dalam memahami pembelajaran Front office Materi Penanganan Check In Tamu Individudi SMKN I Dlanggu adalah model dan pendekatan yang digunakan oleh guru dalam pembelajaran kurang tepat dan membuat siswa menjadi kurang memahami materi tersebut karena secara umum guru di SMKN I Dlanggu masih menerapkan model ceramah, sehingga keterampilan siswa 
dalam mempraktekkan konsep-konsep yang mereka pelajari sangat kurang, dengan demikian pembelajaran dirasakan tidak bermanfaat, tidak menarik dan membosankan. Guru cenderung menggunakan model konvensional, membosankan dan pasif. Selain itu beberapa kelemahan yang diterapkan guru di SMKN I Dlanggu pada Front office Materi Penanganan Check In Tamu Individu di kelas antara lain; masih ada paradigma bahwa pengetahuan yang dimiliki guru dapat dipindahkan begitu saja kepada siswa. Asumsi tersebut, guru memfokuskan pelajaran Front office Materi Penanganan Check In Tamu

Kepribadian petugas kantor epan sangat menentukan terhadap produk dan pelayanan yang diberikan sebab harapan dan keinginan tamu yang akan datang ke hotel adalah menginginkan satu paket yang terbaik antara produk,pelayanan dan proses pemberian layanan tersebut.Atribut kepribadian yang harus dimiliki oleh petugas kantor depan yaitu: 1)Mempunyai pengetahuan yang baik tentang produk hotel (good general knowledge of hotel product), 2) Berpenampilan yang baik dan rapi, 3)Mempunyai keahlian yang baik, 4)Dapat dipercaya, 5)Mampu berdiplomasi, 6)Berinisiatif, 7)Berkelakukan baik, 8) Mempunyai kemamaun yang besar untuk selalu memberikan pelayanan.

Struktur organisasi di kantor depan hotel dipengaruhi oleh besar atau kecilnya hotel,banyak atau sedikit jumlahnya karyawan serta sistem operasional yang digunakan dihotel. Semakin besar hotel semakin rumit pula struktur yang digunakan,begitu pula sebalikinya jika hotel itu kecil, maka struktur organisasinya sederhana. Jika dilihat dari struktur organisasi diatas bahwa pimpinan tertinggi dibagian ini adalah Front office Manager,yang membawai para manager, Chief atau Chef. Adapun tugas- tugas pokok front office (a) menyeleksi, menempatkan, melatih dan mengevaluasi karyawan front office, (b) Memastikan bahwa semua staff di front office menguasai sistem komputer hotel, etika menerima telepon dan standar operasional yang ada di hotel, (c)Menjaga keharmonisan kerja dan penjualan dan pemasaran tentang harga kamar, (d) Menyambut tamu VIP, (e) Menangani keluhan tamu yang tidak bisa di tangani oleh bawahannya, (f) Membuat laporan bulanan tentang daftar tamu,tingkat hunian maupun untung rugi bagian kantor depan, (g) Menjaga kedisiplinan petugas kantor depan dengan memberikan peringatan dan sanksi bagi yang melanggar ketentuan, (h) Meningkatkan kualitas dan prestasi karyawan yang berprestasi dengan memberikan penghargaan, (i) Membuat budget tahunan,menganalisis operasional dan pendapatan hotel secara harian dari sisi pendapata, rata-rat harga kamar.

\section{Metode}

Kegiatan yang dilakukan oleh peneliti pada tahap perencanaan adalah:

a. Peneliti melakukan analisis kurikulum untuk menentukan standar kompetensi dan kompetensi dasar yang disampaikan kepada siswa dengan menggunakan pembelajaran dengan media interaktif.

b. Membuat RPP siklus I dengan model pembelajaran dengan model role playing

c. Membuat lembar observasi siklus I untuk melihat bagaimana kondisi belajar mengajar dikelas ketika latihan dan kerja kelompok dilaksanakan.

d. Membuat Lembar Kerja Siswa siklus I

e. Membentuk kelompok yang bersifat heterogen baik dari segi kemampuan akademis, jenis pembelajaran dengan menggunakan model Role playing pada siklus I

f. Menyusun alat evaluasi pembelajaran berdasarkan perkembangan untuk dilaksanakan pada siklus II serta menyiapkan instrumen pendukung pembelajaran lainnya.

Selama pembelajaran langsung dilakukan observsi untuk mengetahui penggunaan media interaktif dalam meningkatkan hasil belajar front office materi penanganan check in tamu individu pada proses pembelajaran front office. Langkah selanjutnya bagi peneliti dalah pelaksanaan. Pada tahap ini perencanaan yang sudah dibuat peneliti akan dilaksanakan dalam kegiatan pembelajaran. Tahap pengamatan atau observasi dilakukan bersamaan dengan pelaksanaan tindakan. Pada tahap ini peneliti di bantu oleh guru atau teman sejawat untuk mencatat semua hal yang diperlukan dalam penelitian berupa pengumpulan data-data.

Ketika dilaksanakan kegiatan Role playing kebanyakan siswa yang tidak tahu dan tidak paham, sehingga tidak bisa menjawab pertanyaan yang berkenaan dengan soal front office materi penanganan check in tamu individu Karena ketidakpahaman dan ketidakmapuan daam menjawab soal-soal front office, suasana kelas tampak gaduh dan sulit dikendalikan.

Tahap yang terahir merupakann kegiatan untuk mengemukakan kembali apa yang sudah dilakukan. Istilah refleksi berasal dari kata bahasa Inggris reflection yang diterjemahkan dalam bahasa Indonesia. Pada tahap ini peneliti menyimpulkan data atau hasil yang diperoleh selama proses penelitian itu berlangsung. Selain itu juga dimaksudkan sebagai upaya untuk memahami proses, masalah, persoalan, dan kendala nyata dalam proses tindakan. Dalam hal ini peneliti melakukan penilaian sebagai tugas ahir dari siklus. 


\section{Hasil dan Pembahasan}

A. Paparan Hasil Observasi Pra-siklus

Data hasil pretes kelompok siswa yang mendapat perlakuan metode pembelajaran ekspositori dengan, dianalisis dengan teknik statistik uji-t dua sampel independen. Tujuan analisis statistik ini adalah untuk mengetahui tingkat kesetaraan kelompok siswa tersebut.

Tabel 1. Pre Test Rata-rata Nilai Kemampuan front office

\begin{tabular}{ccc}
\hline No. & Kemampuan materi front office & Rata-rata Nilai \\
\hline 1 & Reservation & 69,00 \\
2 & Handling Guest & 69,85 \\
& Rata-rata nilai & 69,425 \\
\hline
\end{tabular}

Berdasarkan isi Tabel 1 terlihat bahwa nilai pretes kelompok siswa sebelum mendapat perlakuan pembelajaran dengan media interaktif adalah 69,425.

B. Paparan Hasil Tindakan Siklus 1

1. Perencanaan Tindakan Siklus 1

Perencanaan di mulai dengan membentuk kelompok diskusi. Siswa yang berjumlah 32 siswa dibagi menjadi 4 kelompok sehingga masing-masing kelompok berjumlah 8 siswa. Materi pelajaran yang diajarkan pada siklus I ini adalah pokok bahasan handling tamue. Proses pembelajaran pokok bahasan handling tamu menggunakan media interaktif yang diterapkan oleh guru secara langsung dalam pembelajaran di kelas.

2. Pelaksanaan Tindakan Siklus 1

Pelaksanaan tindakan siklus I dapat diuraikan sebagai berikut:

a. Guru mengawali pembelajaran dengan mengucapkan salam dan menanyakan jumlah siswa yang hadir.

b. Guru melaksanakan apersepsi.

c. Guru membagi siswa dalam kelompok diskusi, kemudian memberi tugas yang berkaitan dengan penggunaan media interaktif.

d. Guru memberi tugas kepada siswa untuk mempresentasikan di depan kelas hal-hal yang berkaitan handling tamu penggunaan media interaktif, waktu untuk presentasi adalah 3 menit untuk masingmasing kelompok.

e. Guru menindaklanjuti pembelajaran itu dengan menerangkan materi pelajaran tentang hal-hal yang berkaitan dengan handling tamu menggunakan media interaktif, waktu yang digunakan selama 10 menit.

f. Guru bersama-sama siswa mendemonstrasikan penggunaan model Role playing materi handling tamu selama 10 menit.

g. Guru bersama-sama siswa melukukan kegiatan front office materi handling tamu

h. Guru memberikan tugas secara individu selama 15 menit

i. Guru menutup pelajaran dengan mengucapkan salam.

3. Hasil Tindakan Siklus 1

Selama pembelajaran berlangsung dilakukan observasi untuk mengetahui pengaruh kegiatan pembelajaran dalam meningkatkan hasil listening skills siswa dalam proses pembelajaran materi handling tamu. Pada pembelajaran ini siswa yang masuk sebanyak 34 siswa.

Guru mengamati, ternyata pada setiap kelompok masih didapati siswa yang kurang memperhatikan pelajaran yang berkaitan dengan handling tamu, dan masih berbicara dengan teman didekatnya tentang hal-hal yang tidak berkaitan dengan materi pembelajaran. Melalui serangkaian pertanyaan yang disampaikan kepada siswa, sebagian diantaranya belum memahami dan bahkan tidak tau apa yang di diskusikan dalam kelompoknya. 
Tabel 2. Hasil Siklus I

\begin{tabular}{ccc}
\hline No. & Kemampuan handling tamu & Rata-rata Nilai \\
\hline 1 & Reservation & 70,02 \\
2 & Handling Guest & 72,21 \\
& Rata-rata nilai & 71,615 \\
\hline
\end{tabular}

Berdasarkan Tabel 2 tersebut dapat dikatakan bahwa kemampuan handling tamu siswa mengalami peningkatan yang cukup signifikan. Pada Siklus I diperoleh rata-rata nilai 71,615 $(<70,00)$. Hasil tersebut menunjukkan bahwa secara umum, siswa belum tuntas.

4. Refleksi Tindakan Siklus 1

Dalam pelaksanaan kegiatan belajar mengajar pada siklus I yang masih terdapat kekurangankekurangan, Maka perlu adanya revisi untuk dilakukan pada siklus II antara lain :

a. Guru dalam memotifasi siswa hendaknya dapat membuat siswa lebih termotivasi selama proses belajar mengajar berlangsung.

b. Guru harus lebih dekat dengan siswa sehingga tidak ada perasaan takut dalam diri siswa, sehingga siswa lebih berkosentrasi dalam pembelajaran yang berkenaan dengan handling tamu Guru harus lebih bersabar dalam membimbing siswa berdiskusi untuk menemukan hal-hal baru yang berkaitan dengan materi serta dalam mempraktekkan handling tamu secara estafet.

c. Guru harus mendistribusikan waktu secara baik sehingga kegiatan pembelajaran sesuai dengan yang diharapkan.

d. Guru sebaiknya menambah lebih banyak contoh soal dan memberi soal-soal latihan pada siswa untuk dikerjakan pada setiap kegiatan front office.

\section{Paparan Hasil Tindakan Siklus II}

1. Perencanaan Tindakan Siklus II

Perencanaan di mulai dengan membentuk kelompok diskusi. Siswa yang berjumlah 32 siswa dibagi menjadi 8 kelompok sehingga masing-masing kelompok berjumlah 4 siswa. Materi pelajaran yang diajarkan pada siklus 2 ini tetap pada pokok bahasan. Proses pembelajaran pokok bahasan handling tamu ini menggunakan media interaktif yang diterapkan oleh guru secara langsung dalam pembelajaran di kelas.

2. Pelaksanaan Tindakan Siklus II

Pelaksanaan tindakan siklus II dapat diuraikan sebagai berikut:

a. Guru mengawali pembelajaran dengan mengucapkan salam dan menanyakan jumlah siswa yang hadir.

b. Guru melaksanakan apersepsi.

c. Guru membagi siswa dalam kelompok diskusi, kemudian memberi tugas yang berkaitan dengan penggunaan media interaktif.

d. Guru memberi tugas kepada siswa untuk mempresentasikan di depan kelas hal-hal yang berkaitan handle tamu penggunaan model role playing, waktu untuk presentasi adalah 3 menit untuk masingmasing kelompok.

e. Guru menindaklanjuti pembelajaran itu dengan menerangkan materi pelajaran tentang hal-hal yang berkaitan dengan handling tamu menggunakan model role playing, waktu yang digunakan selama 10 menit.

f. Guru bersama-sama siswa mendemonstrasikan penggunaan model Role playing materi handling tamu selama 10 menit.

g. Guru bersama-sama siswa melukukan kegiatan front office materi handling tamu

h. Guru memberikan tugas secara individu selama 15 menit

i. Guru menutup pelajaran dengan mengucapkan salam.

3. Hasil Tindakan Siklus II

Selama pembelajaran berlangsung dilakukan observasi untuk mengetahui pengaruh kegiatan pembelajaran dalam meningkatkan hasil listening skills siswa dalam proses pembelajaran materihandling tamu. Pada pembelajaran ini siswa yang masuk sebanyak 34 siswa.

Guru mengamati, ternyata setiap kelompok siswa memperhatikan pelajaran yang berkaitan dengan front office dengan baik, dan tidak lagi berbicara dengan teman didekatnya tentang hal-hal yang tidak berkaitan dengan materi pembelajaran. 
Tabel 3. Hasil Siklus II

\begin{tabular}{|c|c|c|}
\hline \multirow[t]{4}{*}{ No. } & Kemampuan handling tamu & Rata-rata Nilai \\
\hline & Reservation & 82,32 \\
\hline & Handling Guest & 78,91 \\
\hline & Rata-rata nilai & 80,615 \\
\hline
\end{tabular}

Berdasarkan Tabel 3 tersebut dapat dikatakan bahwa kemampuan front office siswa mengalami peningkatan yang cukup signifikan. Pada Siklus II diperoleh rata-rata nilai 80,615 (> 75,00 yang merupakan KKM Mapel Perhotelan). Hasil tersebut menunjukkan bahwa secara umum, semua siswa tuntas.

Berdasarkan Tabel di atas jumlah nilai observasi kegiatan siswa memuaskan menurut kategori tingkat keaktifan siswa, berarti dalam mengikuti pelajaran siswa sangat aktif, karena anggota kelompok hanya 4 orang dan siswa sudah terbiasa untuk melakukan kegiatan pembelajaran menggunakan media interaktif, sehingga front office siswa semakin meningkat.

5. Refleksi Tindakan Siklus II

Dalam pelaksanaan kegiatan belajar mengajar pada siklus II ini masih terdapat kekurangankekurangan. Maka perlu adanya revisi untuk dilakukan pada siklus II antara lain :

1. Guru dalam memotifasi siswa hendaknya dapat membuat siswa lebih termotivasi selama proses belajar mengajar berlangsung.

2. Guru harus lebih dekat dengan siswa sehingga tidak ada perasaan takut dalam diri siswa, sehingga siswa lebih berkosentrasi dalam pembelajaran yang berkenaan dengan front office

3. Guru harus lebih bersabar dalam membimbing siswa berdiskusi untuk menemukan hal-hal baru yang berkaitan dengan materi serta dalam mempraktekkan hadle tamu secara baik

4. Guru harus mendistribusikan waktu secara baik sehingga kegiatan pembelajaran sesuai dengan yang diharapkan.

5. Guru sebaiknya menambah lebih banyak contoh soal dan memberi soal-soal latihan pada siswa untuk dikerjakan pada setiap kegiatan handle tamu

D. Pembahasan Antar siklus

Sebelum perlakuan diberikan pada masing-masing kelompok, nilai rerata pretes siswa sebelum diberi perlakuan pembelajaran dengan model Role playing adalah 69,425. Setelah siswa diberi perlakuan pembelajaran dengan model Role playing pada siklus I mengalami peningkatan menjadi 71,615, namun hasil ini belum memenuhi kriteria ketuntasan minimal hasil belajar siswa mata pelajaran bahasa inggris yaitu 75,00.

Bila dihitung berdasarkan nilai rerata pretes, kelompok siswa yang diberi perlakuan pembelajaran dengan model Role playing setelah dilaksanaknnya siklus ke II mengalami peningkatan rerata hasil belajar sebesar 80,615-69,425 = 11,19.

Berdasarkan hasil pada sisklus penelitian tersebut di atas, dapat ditunjukkan bahwa ada perbedaan hasil belajar front office antara siswa yang diajar menggunakan metode pembelajaran dengan dibantu model role playing.

Hasil ini sesuai dengan teori yang mengatakan bahwa apabila menginginkan siswa berinteraksi dengan pembelajaran, maka komputer Akomodasi perhotelana adalah pilihan yang paling tepat. Dengan Akomodasi perhotelan, siswa dapat belajar sambil bermain, melakukan peran dan latihan, belajar bagaimana belajar, membuat keputusan, dan bekerjasama. Siswa dapat belajar sesuai dengan materi yang dipelajari diliputi dengan rasa senang.

Dalam proses pembelajaran dengan menggunakan strategi kooperatif, sesuai dengan teori belajar konstruktivisme. Penerapan konstruktivisme dalam proses belajar-mengajar menghasilkan metode pengajaran yang menekankan aktivitas utama pada siswa. Teori pendidikan yang didasari konstruktivisme memandang murid sebagai orang yang menanggapi secara aktif objek-objek dan peristiwa-peristiwa dalam lingkungannya, serta memperoleh pemahaman tentang seluk-beluk objekobjek dan peristiwa-peristiwa itu (Ahmadi dkk, 2004:219).

\section{Simpulan Dan Saran}

Berdasarkan hasil penelitian dan pembahasan yang telah dipaparkan pada bab sebelumnya, maka dapat ditarik kesimpulan sebagai berikut. 
1. Penerapan model Role playing dapat meningkatkan hasil belajar front office materi penanganan check in tamu individu di kelas XI APH 2 SMKN 1 Dlanggu. Nilai rerata hasil belajar front office materi penanganan check in tamu individu siswa setelah mendapat pembelajaran dengan model Role playing sebesar 80,115 lebih tinggi daripada sebelum siswa yang mendapat perlakuan pembelajaran dengan model Role playing yaitu 69,425, artinya setelah adanya perlakuan pembelajaran menggunakan media interaktif terdapat kenaikan perolehan hasil belajar siswa sebesar 11,19. Hal ini dapat diartikan bahwa secara individu, pembelajaran dengan Role playing memiliki pengaruh yang signifikan terhadap hasil belajar front office materi penanganan check in tamu individu

Berdasarkan temuan dan refleksi penerapan pembelajaran dengan model Role playing terhadap hasil belajar front office siswa kelas XI SMKN 1 Dlanggu, maka beberapa saran yang dapat diajukan adalah:

1. Para guru dalam pembelajaran hendaknya menggunakanmodel role playing, khususnya pembelajaran perhotelan pada materi atau pokok bahasan tertentu, sesuai dengan karakteristik pembelajaran.

2. Hasil penelitian ini menunjukkan bahwa penerapan pembelajaran dengan model Role playing dapat meningkatkan hasil belajar front office materi penanganan check in tamu individu siswa lebih baik daripada pembelajaran dengan lainnya.

3. Penelitian ini dilakukan pada subjek penelitian, yaitu siswa SMK kelas XI APH2 saja. Untuk itu, disarankan kepada peneliti selanjutnya agar melakukan penelitian pada kelas yang lain, sehingga dapat diketahui peningkatan front office materi penanganan check in tamu individu siswa pada kelas yang lain.

\section{Daftar Rujukan}

Abdulhak, I. (2000). Ilmu dan Aplikasi Pendidikan.Jakarta: Grafindo.

Anggoro, T. (2007). Metode Penelitian. Jakarta: Universitas Terbuka.

Arikunto, S. (2012). Dasar-Dasar Evaluasi Pendidikan Edisi Ke-2.Jakarta: Rineka Cipta.

Aunurrahman. (2009). Belajar dan Pembelajaran.Cetakan Ke-3. Bandung: Alfabeta.

Badan Nasional Standar Pendidikan. (2009). Undang-Undang Dasar Negara Republik Indonesia 1945 Pasal 31 tentang Pendidikan. Surabaya: Wacana Intelektual.

Badan Nasional Standar Pendidikan. (2009). Undang-Undang No. 20 Tahun 2003 tentang Sistem Pendidikan Nasional. Surabaya: Wacana Intelektual

Basri Hasan. 2017. Penerapan Model Pembelajaran Role Playing Untuk Meningkatkan Hasil Belajar Bahasa Indonesia Siswa Kelas V Sdn 032 Kualu Kecamatan Tambang . Jurnal Pendidikan dan Pengajaran Program Studi Pendidikan Guru Sekolah Dasar FKIP Universitas Riau Volume 1 Nomor 1 Juli 2017

Dalle, J. (2010). Metodologi umum penyelidikan reka bentuk bertokok penilaian dalaman dan luaran: Kajian kes sistem pendaftaran siswa Indonesia. Thesis PhD Universiti Utara Malaysia.

DirektoratJenderal Pendidika Tinggi.(2010).Belajar dan Pembelajaran. Jakarta: Kementerian Pendidikan Nasional.

Djamarah, S. B. (2008). Psikologi belajar. Jakarta: Rineka cipta

Ernawaty \& Kune, S. (2009). Ikhtisar Filsafat Pendidikan. Makassar: Universitas Muhammadiyah Makassar.

Gunawan, R. (2011). Pendidikan MATERI. Bandung: Alfabeta.

Komalasari, K. (2010). Pembelajaran Kontekstual Konsep dan Aplikasinya. Bandung: PT. Refika Aditama.

Nuryanti, L. (2008). Psikologi Anak. Jakarta: PT. Indeks

Rusdayanto, F. (2010). Potret Buram Pendidikan Kita. Jakarta: PT. Pena Emas. 
Rusman. (2011). Model-model pembelajaran mengembangkan Profesionalisme Guru. Jakarta: PT. Rajagrafindo Persada.

Sardiman. (2008). Interaksi Dan Motivasi BelajarMengajar. Jakarta: PT. Raja Grafindo Persada.

Sanjaya, W. (2009). Perencanaan dan Desain Sistem Pembelajaran. Jakarta: Kencana.

Sanjaya, W. (2011). Strategi Pembelajaran Berorientasi Standar Proses Pendidikan. Jakarta: Kencana Prenada Media.

Satori, D. (2008). Profesi Keguruan. Jakarta: Universitas Terbuka.

Saud, S. U. (2009). Inovasi Pendidikan. Bandung: Alfabeta.

Semiawan, C. (2008). Belajar dan Pembelajaran Pra Sekolah dan Sekolah Dasar. Jakarta: PT. Macanan Jaya Cemerlang.

Slameto.(2003).Belajar dan Faktor-Faktoryang mempengaruhinya. Jakarta: Rineka Cipta

Solihatin,E. \& Raharjo.(2007).Cooperative Learnig Analisis Model Pembelajaran IPS. Jakarta: Bumi Aksara.

Suprijono,A. (2010). Cooperatif Learning, Jakarta:Kencana Yudistira.

Trianto.(2009).Mendesain Model Pembelajaran Inovatif ProgresifKonsep Landasan dan Implementasinya Pada KurikulumTingkat Satuan Pendidikan.Jakarta: Kencana Prenada Media Group

Wardhani, I. \&Wihardit, K. (2007). Penelitian Tindakan Kelas. Jakarta: Universitas Terbuk 